\title{
Prediction of Resection Weight in Reduction Mammaplasty Based on Anthropometric Measurements
}

\author{
Yavuz Kececi Emin Sir \\ Department of Plastic and Reconstructive Surgery, Izmir Teaching and Research Hospital, Turkey
}

\section{Keywords}

Anthropometric measurements · Breast asymmetry .

Breast reduction - Reduction mammoplasty .

Resection weight

\section{Summary}

Background: The aim of this study was to develop a simple, clinically useful method to accurately predict resection weight in women undergoing reduction mammaplasty. Patients and Methods: 39 women undergoing breast reduction participated in the study. Sternal notch to nipple distance, nipple to inframammary fold distance (NIMF), medial end point to nipple distance (MN), lateral endpoint to nipple distance (LN), superior border of the breast to nipple distance (SN), breast circumference $(B C)$, and chest circumference (CC) were measured. 5 other predicting variables were also derived; horizontal breast measurement $(\mathrm{H})$ by adding $\mathrm{MN}$ to $L N$, vertical breast measurement (V) by adding NIMF to $\mathrm{SN}$, the product of $\mathrm{H}$ and $\mathrm{V}\left(\mathrm{H}^{*} \mathrm{~V}\right)$, the product of $\mathrm{H}$ and NIMF $\left(H^{*} \mathrm{NIMF}\right)$, and the difference between $B C$ and $C C$ (D). Regression analysis was used to compose a formula for predicting resection weight. Results: Among the predicting variables, $\mathrm{H}^{*} \mathrm{NIMF}$ measurements had the highest correlation coefficient value (Pearson correlation $=0.809$ ) with the resection weight. The following formula was obtained with regression analysis: Predicted resection weight $=\left(1.45 \times \mathrm{H}^{*} \mathrm{NIMF}\right)+(31.5 \times \mathrm{D})-576$. Conclusion: Breast resection weights can be accurately predicted by the presented method based on anthropomorphic measurements.

\section{Introduction}

There are many studies indicating that symptomatic breast hypertrophy is a significant health burden and reduction mammaplasty successfully relieves the symptoms related to macromastia [1-4]. However, financial coverage of the operation is usually restricted by the insurance companies since they are inclined to describe reduction mammaplasty as an aesthetic procedure. They require the documentation of conservative therapy for treatment of macromastia symptoms, and are being increasingly rigid in their requirements of resected tissue weights before approval authorization [5]. Although some companies choose a standard value as a minimum reduction weight, most of them base weight reduction minimums on body surface area or body mass index (BMI) $[6,7]$. Therefore, accurately predicting tissue resection weight becomes important for most patients, not just for patients requiring approximately $500 \mathrm{~g}$ resection weight. Accurate estimation of the weight of tissue to be resected during reduction mammaplasty can be very difficult for inexperienced plastic surgeons. Even experienced surgeons find these predictions difficult, particularly in patients with large and pendulous breasts [8].

Asymmetry is a problem in many women with breast hypertrophy. Tenna et al. [9] reported a difference of greater than $200 \mathrm{~g}$ between right and left breasts in $20 \%$ of their patients. Volume difference greater than $50 \mathrm{cc}$ was found in $65 \%$ of women in another study [10]. The requirement of asymmetry treatment is not uncommon in breast reduction surgery and achieving symmetry may be difficult.

Hence, reliable and objective breast resection weight determination prior to surgery would greatly aid the surgeon in achieving optimal breast symmetry and in satisfying reimbursement requirements $[10,11]$. In addition, it may also help in the selection of the surgical method since short scar techniques may be preferred in cases requiring less than $500 \mathrm{~g}$ per side [12].

\section{KARGER \\ Fax +497614520714 \\ Information@Karger.com}

www.karger.com (c) 2014 S. Karger GmbH, Freiburg

1661-3791/14/0091-0041\$39.50/0

Accessible online at:

www.karger.com/brc 
The purpose of this study was to develop a simple, clinically useful method to predict resection weight accurately in women undergoing reduction mammaplasty using objective parameters that can be easily measured preoperatively. Anthropomorphic measurements were used as predicting parameters.

\section{Patients and Methods}

Local Ethics Committee approval was granted for the study. All patients undergoing reduction mammaplasty for symptoms of macromastia between June 2012 and December 2012 were invited to participate in this study. The participant patients signed an informed consent term. The Declaration of Helsinki protocol was followed.

Height, weight, sternal notch to nipple distance (SNN), nipple to inframammary fold distance (NIMF), medial end point to nipple distance $(\mathrm{MN})$, lateral endpoint to nipple distance (LN), and superior border of the breast to nipple distance (SN) were measured. The lateral endpoint was determined as a point on the projection of the anterior axillary line on the mammary tissue (fig. 1). In addition, breast circumference (BC) was measured across the fullest part of the breast over the nipples, and

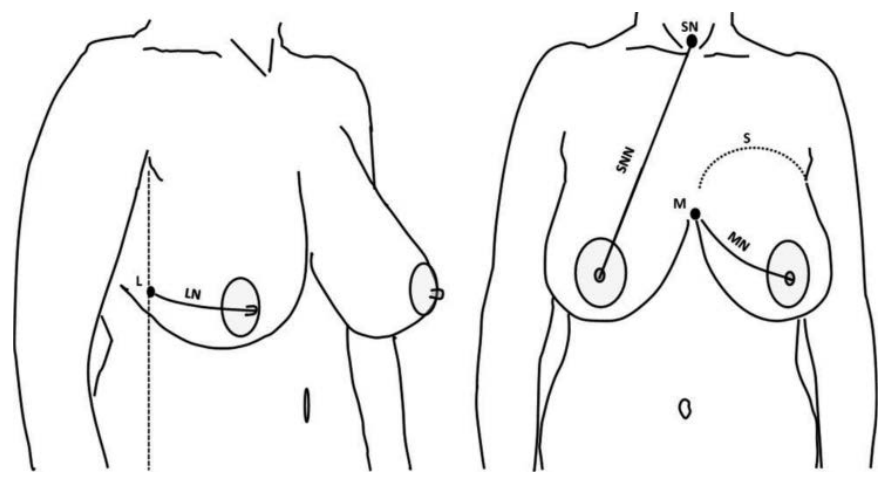

Fig. 1. Anthropometric breast measurements. Left: Lateral endpoint (L) of the breast is determined as a point on the projection of the anterior axillary line (vertical dotted line). $\mathrm{LN}=$ nipple to the lateral endpoint distance. Right: $\mathrm{SNN}=$ nipple to sternal notch $(\mathrm{SN})$ distance; $\mathrm{MN}=$ nipple to medial end point $(\mathrm{M})$ distance; $\mathrm{S}=$ superior endpoint of the breast. Measurements were obtained with the arms down.

Table 1. The results of reliability analysis of the variables

\begin{tabular}{lll}
\hline Measurement & ICC & $95 \%$ CI \\
\hline SNN & 0.891 & $0.855-0.927$ \\
MN & 0.954 & $0.937-0.967$ \\
NIMF & 0.969 & $0.947-0.983$ \\
LN & 0.834 & $0.807-0.861$ \\
SN & 0.685 & $0.551-0.785$ \\
CC & 0.919 & $0.871-0.841$ \\
BC & 0.887 & $0.828-0.916$ \\
\hline
\end{tabular}

ICC $=$ intraclass correlation coefficient, $\mathrm{CI}=$ confidence interval, $\mathrm{SNN}=$ sternal notch to nipple distance, $\mathrm{MN}=$ medial end point to nipple distance, NIMF = nipple to inframammary fold distance, $\mathrm{LN}=$ lateral endpoint to nipple distance, $\mathrm{SN}=$ superior border of the breast to nipple distance, $\mathrm{CC}=$ chest circumference, $\mathrm{BC}=$ breast circumference. chest circumference (CC) under the breast at the level of the inframammary fold. Besides these 7 anthropomorphic measurements taken directly from the chest, 5 more predicting variables were derived; horizontal breast measurement $(\mathrm{H})$ by adding $\mathrm{MN}$ to $\mathrm{LN}$, vertical breast measurement $(\mathrm{V})$ by adding NIMF to SN, $\mathrm{H}^{*} \mathrm{~V}, \mathrm{H}^{*} \mathrm{NIMF}$, and the difference between $\mathrm{BC}$ and $\mathrm{CC}(\mathrm{D})$.

Measurements were made with a measuring tape and the results were taken to the nearest whole number. All measurements were made with the women standing in the normal anatomic position, with arms at the sides, palms forward and head straight ahead. BMI was calculated as the weight in kilograms divided by the height in meters squared. All tissue specimens were weighted in the operating theater at the time of resection using a calibrated scale. To test for reliability, each measurement was taken twice. The first author (Y.K.) performed the first measurement and the clinical nurse practitioner repeated it 1 week later when the first measurement markings disappeared. This was done for all patients.

\section{Statistics}

Pearson correlations were computed between predicting parameters and resection weight. Stepwise regression analysis was performed by entering the breast weight as a dependent variable and the predicting parameters that were significantly correlated with resection weight as independent variables into the model. Regression analysis was used to determine whether a combination of predictors or a single predictor would result in a more accurate prediction. The model of best fit was chosen based on the $R^{2}$ regression coefficients.

The level of statistical significance was determined as $\mathrm{p}<0.05$. For evaluating the reliability of the measurements, an intraclass correlation coefficient (ICC) was used. A higher coefficient value reflects higher reliability and lower standard error of measurement. It has been established that ICC can vary from 0 to 1 and values above 0.80 are regarded as evidence of perfect reliability [13]. All statistics were performed with SPSS version 20.0 (SPSS Inc, Chicago, IL, USA).

\section{Results}

Thirty-nine women undergoing breast reduction participated in the study and measurements were performed on 78 breasts. The mean resection weight was $809 \mathrm{~g}$ (SD 387). The reliability analysis of measurements revealed that, except for the SN measurement, all direct anthropomorphic measurements had perfect reliability. There was a significant difference between the value obtained by the 2 people assessing the SN measurement. ICC single measures using an absolute agreement definition was 0.685 (confidence interval (CI) $95 \%, 0.551-0.785)$. For other 6 direct anthropomorphic measurements, ICC single measures using an absolute agreement definition were between 0.834 and 0.969 (table 1). Thus, SN was accepted as an unreliable measurement. SN and its derivative variables $\left(\mathrm{V}\right.$, and $\left.\mathrm{H}^{*} \mathrm{~V}\right)$ were not used as variables in predicting analyses.

Among the predicting variables, $\mathrm{H}^{*} \mathrm{NIMF}$ measurements had the highest correlation coefficient value (Pearson correlation coefficient $=0.809$ ) with the resection weight. All predicting variables except $\mathrm{CC}$ were correlated significantly with resection weight. The mean and correlation coefficient values with the resection weight of all measurements are given in table 2 . 
Table 2. The mean and correlation coefficient values with the resection weight of measurements

\begin{tabular}{lcl}
\hline Predicting variables & Mean (SD) & $\begin{array}{l}\text { Correlation coefficient } \\
\text { with RW }\end{array}$ \\
\hline SNN & $32.1(3.7)$ & $0.686^{* *}$ \\
NM & $18.1(2.9)$ & $0.623^{* *}$ \\
NIMF & $13.8(2.4)$ & $0.682^{* *}$ \\
LN & $18.5(3.0)$ & $0.751^{* *}$ \\
CC & $86.9(9.3)$ & 0.236 \\
BC & $106.2(11.2)$ & $0.552^{*}$ \\
BC-CC & $19.7(5.6)$ & $0.769^{* *}$ \\
BMI & $28.1(4.3)$ & $0.410^{* *}$ \\
H & $36.6(5.2)$ & $0.773^{* *}$ \\
H*NIMF & $511.3(150.0)$ & $0.809^{* *}$ \\
\hline
\end{tabular}

$\mathrm{SD}=$ standard deviation, $\mathrm{RW}=$ resection weight, $\mathrm{H}=$ horizontal breast measurement, $\mathrm{H}^{*} \mathrm{NIMF}=$ product of $\mathrm{H}$ and NIMF.

* Correlation is significant at the 0.05 level.

** Correlation is significant at the 0.01 level.

In regression analysis, the strongest correlation was observed after incorporating 2 parameters; $\mathrm{H}^{*} \mathrm{NIMF}$ and $\mathrm{D}$. The following formula was obtained:

Predicted resection weight $(\mathrm{g})=\left(1.45 \times \mathrm{H}^{*} \mathrm{NIMF}\right)+(31.5$ $\times$ D) -576 .

The formula was associated with an adjusted $R^{2}$ of 0.786 , suggesting that almost $80 \%$ of resection weight variability was accounted for by this model. When compared with actual resection weight, predicted resection weight demonstrated good concordance (fig. 2). The mean absolute difference between predicted and actual resection weights (residuals) was $0.0 \mathrm{~g}$ (SD $171 \mathrm{~g}$ ), ranging from $-300 \mathrm{~g}$ to $337 \mathrm{~g}$.

\section{Discussion}

The aim of our study was to devise a method for predicting breast resection weight that is readily available, simple to apply, and precise enough for clinical use. We developed a predicting resection weight formula based on anthropometric measurements. This formula was found to account for the majority of the observed variability in resection weights.

A significant correlation between breast volume and resection weight in patients undergoing reduction mammoplasty has been reported [14]. There are numerous methods for measuring breast volume, such as water displacement [15], casting [16], the Grossman-Roudner device [17], biostereometric analysis with stereometric cameras [18], and radiological measurements [19]. However, even if volume can be measured, it is still a matter of presumption or estimation how much is going to be removed since mammary physiognomy of the patients varies. Thus, a certain breast volume or cup size cannot be targeted. With that in mind, the utility of having a breast volume measurement may be minimal, and surgeons attach importance to the prediction of resection weights

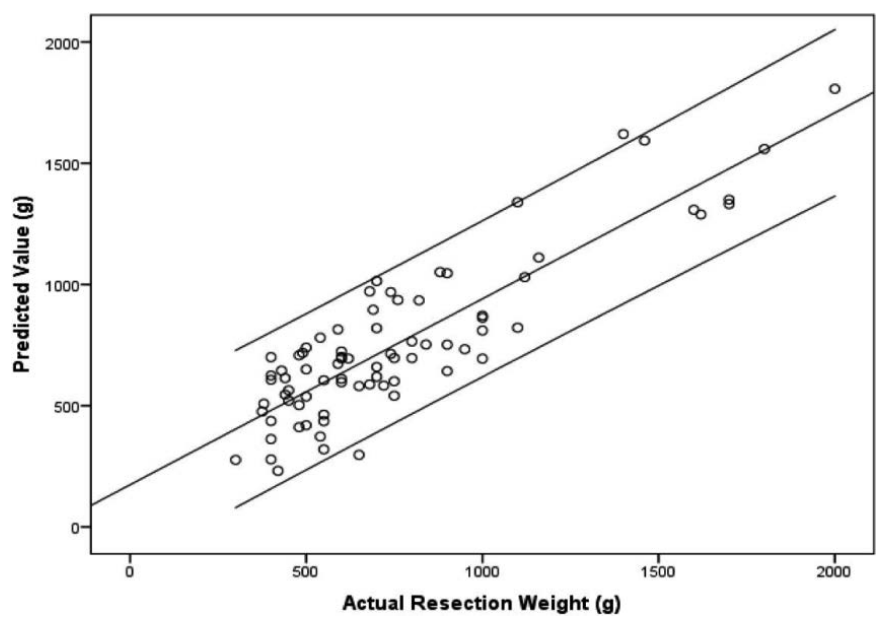

Fig. 2. The scatter plot of predicting values versus actual resection weights. Predicted resection weight was in close agreement with actual resection weight with a narrow $95 \%$ confidence interval.

rather than breast volume. Therefore, this study was designed to develop a direct breast resection weight prediction method.

Anthropomorphic measurements are relatively feasible, cheap, and quick to perform and have been found to be the most convenient method for breast volume determination [14, 20]. Some authors have used anthropomorphic measurements in establishing a method for predicting resection weight. Regnault and Daniel [21] presented a formula to predict resection weight to attain the desired bra size. Their formula was based on differential measurements of breast circumference measured across the nipples and band size measured just under the arms at the level of the axilla. Although this method benefits preoperative planning and predicting cup size, it has little contribution to the prediction of resection weights since the method aims at calculating how much breast tissue has to be removed to reach the desired bra cup size [22]. In addition, with this method it is not possible to predicte the different weights to be removed from each breast in cases of significant breast asymmetry.

Sommer et al. [23] developed a formula for predicting resection weights based on a single preoperative measurement, SNN distance. Although generally successful in estimating resection weights in larger breasts, the accuracy rate was 50\% in determining whether resection weight was over $500 \mathrm{~g}$ or not in women undergoing resection of breast weight of between 400 and 600 g. Descamps et al. [10] used only 2 vertical measurements; NIMF distance and SNN distance, and found that these 2 measurements had significant correlation with breast resection weight. Appel et al. [24], by appending BMI to these 2 measurements, developed another formula similar to the former one. On the other hand, Kocak et al. [11] took the gauge of SNN distance, and vertical and horizontal breast surface measurement. They found that the parameter obtained by multiplying the vertical and horizontal measurements had a relatively high correlation coefficient $(r=0.95)$ with breast 
tissue resection weight. They postulated that SNN might be affected by the length of the thorax and formulas based on breast-only measurements had more accurate results. In the present study, H*NIMF measurements had the highest correlation with breast tissue resection weight (Pearson correlation, $r=0.809$ ) and regression analysis added the difference between $\mathrm{BC}$ and $\mathrm{CC}$ parameter to the resection weight estimation formula.

The female breast is noted for its diverse physiognomy, making accurate, reproducible measurements very difficult [24]. Most surgeons do not use anthropometric measurements assuming that they are compromised by a lack of clearly defined landmarks. For this reason, we assessed the reliability of the measurements in this study. The results revealed that, except for the SN measurement, all measurements had the perfect internal consistency and were reliable. Therefore, it seems reasonable to state that taking anthropomorphic measurements of the breast using a measuring tape is a reliable method.

This method can be performed in clinical practice. It is difficult, for especially inexperienced surgeons, to assess breast cosmesis and symmetry while the patient is in the supine position during an operation. The method could help in making a decision about the amount of breast resections during the actual surgery to achieve symmetry. Furthermore, it would also aid in fulfilling the policy required by insurance companies.

Patients usually denote their desired breast volume as a bra size. However, most women have only a vague idea about their bra size and often wear the wrong size [25, 26]. Moreover, there is no standardization of size between different manufacturers [27].

Although this formula was found to account for most of the observed variability in breast resection weights, there was a considerable difference between predicted and actual resection weights in some patients. These residual weights could result postoperatively in payment refusal by a third party (e.g. insurer) and put a significant financial burden on patients. Thus, this issue has to be discussed in detail with patients prior to surgery.

The limitation of this study was its small sample size. However, in addition to the derived 3 variables, 6 anthropomorphic measurements taken directly from the chest were used to develop the formula, and the reliability of the direct measurements was demonstrated. The only minor to moderate amount of residuals between predicted and actual resection weights reveals that this formula works well in predicting resection weight. Another concern might be that the formula for prediction of resection weight is based only on anthropometric measurements, and that patient's subjective wishes and expectations should also be considered in making a decision about resection weight. Therefore, the benefits of the accuracy of the formula may lessened by inordinate patient expectations.

The formula worked well even in patients with pendulous macromastia. Nevertheless, it should be taken into account that all women participating in this study had macromastia, and that this formula might not be useful in women with pendulous breasts in whom macromastia is not primary concern.

In conclusion, breast resection weights can be accurately predicted by the presented method based on anthropomorphic measurements. This method can help in dealing with debatable insurance coverage questions and in making patient consultation and communication more transparent. In addition, it can also be used as an intraoperative guide when breast asymmetry is present.

\section{Disclosure Statement}

The authors declare no conflict of interest.

\section{References}

1 Blomqvist L, Eriksson A, Brandberg Y: Reduction mammaplasty provides long-term improvement in health status and quality of life. Plast Reconstr Surg 2000;106:991-997.

2 Chao JD, Memmel HC, Redding JF, et al.: Reduction mammaplasty is a functional operation, improving quality of life in symptomatic women A prospective, single-center breast reduction outcome study. Plast Reconstr Surg 2002; 110:1644 1652; discussion 1653-1654.

$>3$ Thoma A, Sprague S, Veltri K, et al.: A prospective study of patients undergoing breast reduction surgery: Health-related quality of life and clinical outcomes. Plast Reconstr Surg 2007;120: 13-26.

$\checkmark 4$ Spector JA, Karp NS: Reduction mammaplasty: A significant improvement at any size. Plast Reconstr Surg 2007;120:845-850.

$\checkmark 5$ Schnur PL, Hoehn JG, Ilstrup DM, et al.: Reduction mammaplasty: Cosmetic or recon structive procedure? Ann Plast Surg 1991;27:232237.

6 Seitchik MW: Reduction mammaplasty: Criteria for insurance coverage. Plast Reconstr Surg 1995; 95:1029-1032.

7 Nguyen JT, Wheatley MJ, Schnur PL, et al.: Reduction mammaplasty: A review of managed care medical policy coverage criteria. Plast Reconstr Surg 2008;121:1092-1100.

8 Eder M, Papadopulos NA, Kovacs L: Breast volume determination in breast hypertrophy. Plast Reconstr Surg 2007;120:356-357.

$\checkmark 9$ Tenna S, Cogliandro A, Cagli B, et al.: Breast hypertrophy and asymmetry: A retrospective study on a sample of 344 consecutive patients. Acta Chir Plast 2012;54:9-12.

10 Descamps MJ, Landau AG, Lazarus D, et al.: A formula determining resection weights for reduction mammaplasty. Plast Reconstr Surg 2008; 121:397-400.
11 Kocak E, Carruthers KH, McMahan JD. A reliable method for the preoperative estimation of tissue to be removed during reduction mammaplasty. Plast Reconstr Surg 2011; 127:1059-1064.

12 McCulley SJ, Rousseau TE: A modified Chiari L short-scar mammaplasty: The technique and results. Br J Plast Surg 1999;52:112-117.

13 Lee J, Koh D, Ong CN: Statistical evaluation of agreement between two methods for measuring a quantitative variable. Comput Biol Med 1989;19: 61-70.

14 Eder M, Grabhorn A, Waldenfels FV, et al.: Prediction of breast resection weight in reduction mammaplasty based on 3-dimensional surface imaging. Surg Innov 2013;20:356-364.

15 Schultz RC, Dolezal RF, Nolan J: Further applications of Archimedes' principle in the correction of asymmetrical breasts. Ann Plast Surg 1986;16: 98-101. 
16 Edsander-Nord A, Wickman M, Jurell G: Measurement of breast volume with thermoplastic casts Scand J Plast Reconstr Surg Hand Surg 1996;30: 129-132.

17 Grossman, AJ, Roudner LA: A simple means for accurate breast volume determination. Plast. Reconstr. Surg 1980;66:851-852.

18 Loughry CW, Sheffer DB, Price TE Jr, et al.: Breast volume measurement of 248 women using biostereometric analysis. Plast Reconstr Surg 1987;80:553-558.

19 Pozzobon AV, Sabino Neto M, Veiga DF, et al.: Magnetic resonance images and linear measurements in the surgical treatment of breast asymmetry. Aesthetic Plast Surg 2009;33:196-203.
20 Bullstrode NW, Shrotria S: Prediction of cosmetic outcome following conservative breast surgery using breast volume measurements. Breast 2001; 10:124-126.

21 Regnault P, Daniel RK: Breast reduction; in Regnault P, Daniel RK (eds): Aesthetic Plastic Surgery: Principles and Techniques, Chapter 21. Boston, MA, Little Brown, 1984, pp 499-538.

22 Turner AJ, Dujon DG: Predicting cup size after reduction mammaplasty. Br J Plast Surg. 2005;58: 290-298.

23 Sommer NZ, Zook EG, Verhulst SJ: The prediction of breast reduction weight. Plast Reconstr Surg 2002;109:506-511.
24 Appel JZ III, Wendel JJ, Zellner EG, et al.: Association between preoperative measurements and resection weight in patients undergoing reduction mammaplasty. Ann Plast Surg 2010;64:512-515.

25 Westreich M: Anthropomorphic breast measurement: Protocol and results in 50 women with aesthetically perfect breasts and clinical application. Plast Reconstr Surg 1997;100:468-479.

26 Greenbaum AR, Heslop T, Morris J, et al.: An investigation of suitability of bra fit in women referred for reduction mammaplasty. Br J Plast Surg 2003;56:230-236.

27 Pechter EA: A new method for determining bra size and predicting postaugmentation breast size. Plast Reconstr Surg 1998;102:1259-1265. 